\title{
Complications and pregnancy outcome in women with preeclampsia and eclampsia
}

\author{
G. Thiripurasundari ${ }^{1}$, D. M. Christe ${ }^{2 *}$, S. Shobha $^{1}$, V. Sangeetha ${ }^{1}$, Suganya Sevugaperumal $^{1}$
}

\begin{abstract}
${ }^{1}$ Department of Obstetrics and Gynecology, Institute of Obstetrics and Gynecology, Chennai, Tamil Nadu, India ${ }^{2}$ Department of Research in Human Reproduction, IOG, National Institute for Research in Human Reproduction- Field Unit (NIRRH-FU) Indian Council of Medical Research Chennai, Tamil Nadu, India
\end{abstract}

Received: 05 November 2019

Revised: 02 December 2019

Accepted: 10 December 2019

\section{*Correspondence:}

Dr. D. M. Christe,

E-mail: drdmchriste@gmail.com

Copyright: (c) the author(s), publisher and licensee Medip Academy. This is an open-access article distributed under the terms of the Creative Commons Attribution Non-Commercial License, which permits unrestricted non-commercial use, distribution, and reproduction in any medium, provided the original work is properly cited.

\section{ABSTRACT}

Background: One of the complications of pregnancy which till today challenges the obstetrician is preeclampsia and its severe form of eclampsia. Objective of this study was to find out the complications and outcome of pregnant women with preeclampsia and eclampsia admitted in a tertiary referral center.

Methods: Case records, in labor room, were scrutinized to find out the number and the outcome of pregnancy, in women admitted with preeclampsia or eclampsia in the year 2018.

Results: Pregnant women admitted with preeclampsia or eclampsia numbered 2511 and, 109 women developed complications. Maternal complications, were more often seen in mothers, (62.4\%) of female babies. Only $37.6 \%$ of mothers of male babies developed complications. Complications seen were Renal complications in $34.8 \%$, Hematological complications in $33 \%$, Neurological complications in $25.6 \%$, Pulmonary complications in $16.5 \%$, ophthalmological complications in $11 \%$ and Sepsis in $6.4 \%$ and MODS in 10\%. Of total maternal deaths, 34\% was caused by complications of preeclampsia or eclampsia. Major cause of maternal death was MODS and Pulmonary complications. Nearly, $62.3 \%$ of babies born had birth weight of $1.8 \mathrm{~kg}$ and nearly one-third of babies $(26.6 \%)$ were dead born.

Conclusions: The incidence of preeclampsia and eclampsia in our referral center for the year 2018 was $15 \%$, and $4.3 \%$ of women developed complications, and $6 \%$ died, making preeclampsia and eclampsia the causative factor for $34 \%$ of total maternal deaths. Major maternal complications were Renal, Hematological, Neurological, Pulmonary and MODS. Complications of preeclampsia were more often present in $62.4 \%$ mothers of female babies in contrast to $37.6 \%$ of mothers of male babies. Nearly one-third of babies $(26.6 \%)$ were dead born.

Keywords: Complications, Eclampsia, HELPP syndrome, Preeclampsia, Renal

\section{INTRODUCTION}

One of the complications of pregnancy which till today challenges the obstetrician is preeclampsia and its severe form of eclampsia. Pregnancy is at times found to be associated with a complication, preeclampsia which is a multiorgan disease of unknown etiology characterized by de novo development of hypertension and proteinuria after 20 weeks of gestation. It is defined as a triad of hypertension, edema, and proteinuria. Modern definition does not include edema because of a lack of specificity. Edema is neither sufficient nor necessary to confirm the diagnosis of preeclampsia. The clinical findings of preeclampsia can manifest as either maternal syndrome 
alone (hypertension and proteinuria. $0.3 \mathrm{~g} / 24$ hour-urine with or without other multisystem dysfunction) or in association with the fetal syndrome (fetal growth restriction, oligohydramnios). ${ }^{1}$ The appearance of proteinuria remains an important diagnostic criterion to differentiate from gestational hypertension. ${ }^{2}$ Proteinuria is defined as a 24-hour urinary protein excretion exceeding $300 \mathrm{mg}$, a urine protein:creatinine ratio of 0.3 , or persistent $30 \mathrm{mg} / \mathrm{dL}$ (11 on dipstick) protein in random urine samples. The incidence of preeclampsia in India is estimated to be 8 to $10 \%$. The incidence of preeclampsia and eclampsia in our referral centre for the year 2018 was $15 \%$.

\section{Etiopathogenesis}

The exact nature of the primary cause of pre-eclampsia still remains unknown. The key features in the pathogenesis of preeclampsia, is seen as an abnormal trophoblastic invasion of spiral arteries, inappropriate endothelial cell activation, and exaggerated inflammatory response. ${ }^{3}$ The pre-eclamptic syndrome has been hypothesized as a two-stage disorder.

The primary stage involves abnormal placentation. The second stage of preeclampsia involves the conversion of this earlier described uteroplacental maladaptation to the maternal systemic syndrome of preeclampsia.

\section{Eclampsia}

Eclampsia is an extremely severe form of preeclampsia. It is characterized by sudden onset of generalized tonicclonic convulsion or coma in pregnancy or postpartum, unrelated to other cerebral conditions, in patients with signs and symptoms of preeclampsia.

\section{Pathophysiology}

The pathophysiology of eclampsia is still not conclusively elucidated. Autopsy studies have shown cerebral edema, cortical and subcortical white matter microinfarcts, pericapillary and parenchymal bleeding and vascular lesions predominantly in the occipital and watershed areas. The dominant finding in MRI is subcortical white matter edema involving the posterior portions of the cerebral hemispheres bilaterally. Additional findings are areas of petechial hemorrhage and ischemia, particularly in the occipital and parietal occipital regions.

Tertiary referral center in Chennai, Tamil Nadu, South India.

This is a retrospective analytical study. Approval for conducting this study was given by the institutional ethics committee. Consent was not obtained from individual study participants as data was accessed from Medical records section only and was analyzed maintaining complete patient confidentiality.
Objective of this study was to find out the complications and outcome of pregnant women with preeclampsia and eclampsia admitted in a tertiary referral center.

\section{METHODS}

In this study we assessed the case records, of women admitted for delivery with the complication of preeclampsia or eclampsia in the year 2018, and formed the study population. All case records of women with the diagnosis of preeclampsia or eclampsia were scrutinized. Out of these, records of women who had developed complications associated with preeclampsia and eclampsia, which was the criteria for inclusion, were selected and formed the study group. All records of women who had developed complications of renal, hematological, HELPP syndrome, neurological including headache and psychosis, pulmonary, ophthalmological, sepsis and multi-organ dysfunction syndrome (MODS) were included. Case records of women with preeclampsia or eclampsia who had not developed any of the abovementioned complications, and who had preexisting disorders developed before pregnancy, which were the criteria for exclusion, were excluded. The number of maternal deaths among the study group was also noted. Details of baby at delivery, whether it was born alive or dead, birth weight and sex of the baby were also noted. Standard statistical analysis, of the data collected was done.

\section{RESULTS}

In the study period of one year, we observed that 2511 women were admitted with the complication of preeclampsia or eclampsia.

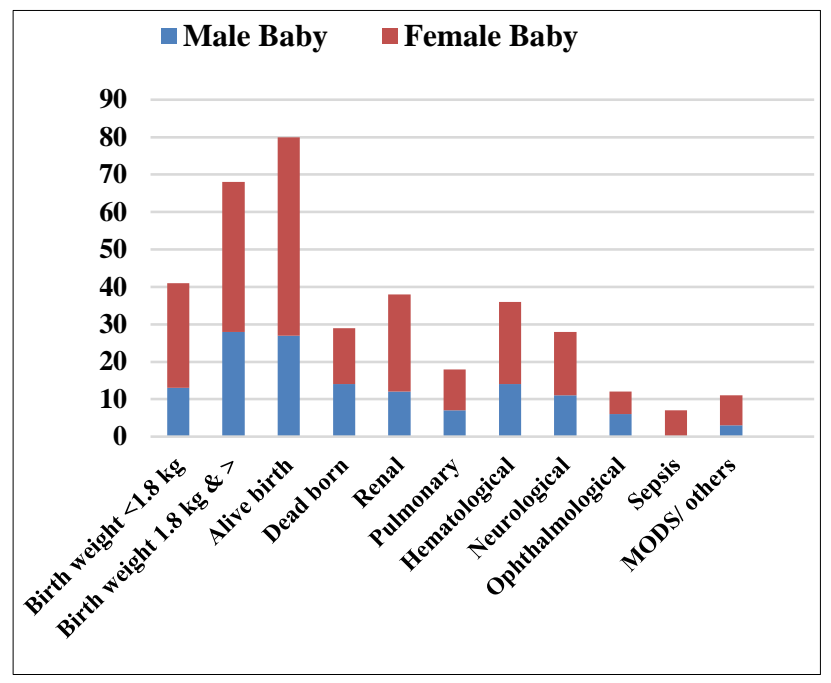

Complications associated with preeclampsia or eclampsia were noted in 109 women and $37.7 \%$ of babies were born with birth weight below $1.8 \mathrm{~kg}$. $62.3 \%$ of babies were born with birth weight $1.8 \mathrm{~kg}$ and above. $26.6 \%$ of babies were dead born. $73.4 \%$ of babies were born alive.

Figure 1: Maternal and neonatal outcome in women with preeclampsia/eclampsia. 
A total number of 109 women developed complications because of preeclampsia and eclampsia and they constituted the study group. The total number of deliveries for the year 2018 was 15967 and there were a total of 18 maternal deaths. A significant number of maternal deaths forming nearly $34 \%$ of all maternal deaths $(n=6)$, for the year 2018, was caused by complications which had developed because of preeclampsia or eclampsia. The majority of babies forming $62.3 \%$ of the total number of babies born had a birth weight of $1.8 \mathrm{~kg}$ and above. The percentage of babies that were dead born was $26.6 \%$ and formed about $1 / 3^{\text {rd }}$ of the total number of babies born.

In our study, we found renal complications in $34.8 \%$ of women and hematological complications in $33 \%$ of women. Hematological (including HELLP syndrome) and renal complications were more often observed in women with preeclampsia and eclampsia.

Neurological complications were also recorded in $25.6 \%$. We observed the complications of cerebral venous thrombosis, cerebral hemorrhage, encephalopathy in our study group of women. Other complications such as psychosis and headache were seen in a small number of women. Pulmonary complications and ophthalmological complications developed in $16.5 \%$ and $11 \%$ of women (Figure 1). Less often seen were septic complications which was noted in $6.4 \%$ of women. The fulminant complication of preeclampsia and eclampsia dreaded by all obstetricians namely multi-organ dysfunction syndrome (MODS) was noted in $10 \%$, of women.

\section{DISCUSSION}

\section{Teenage mothers}

It was significant to note that among the group of teenage women, that $50 \%$ chance of survival was seen among the neonates with $50 \%$ born alive. The pulmonary, neurological complications and MODS was recorded in $16 \%$ of this group of women. ${ }^{4-6}$ Among this group of women, the most often developing complication was hematological complications which was recorded in $33 \%$ of women and ophthalmological complications which was recorded in $33 \%$ of women. ${ }^{7,8}$ It is significant to note that no renal and septic complications were seen in teenage women admitted for delivery with complication of preeclampsia and eclampsia. There were no maternal deaths in this group of women (Figure 2).

\section{Elderly mothers}

When we analyzed the records of elderly women aged 35 years and above, we observed that the percentage of women in this age group constituted $8.25 \%$ of the study group. Nearly $44.4 \%$ of babies were born with birth weight of less than $1.8 \mathrm{~kg}$. $55.5 \%$ of babies were born with birth weight more than $1.8 \mathrm{kgs}$ and above. All 9 babies were born alive. It is significant to note that there were no deaths in babies with a viable age of 30 weeks and above born to elderly women with pregnancy complications of preeclampsia and eclampsia. Major complications of renal complications were seen in $55.5 \%$ of women. Pulmonary complications were seen in $22.2 \%$ of women. Hematological complications were seen in $22.2 \%$ of women. Neurological complications were seen in $33 \%$ of women. Ophthalmological complications were seen in $11.1 \%$ of women. It is also important to note there was no complication of sepsis and multi-organ dysfunction syndrome in elderly women admitted for delivery with preeclampsia or eclampsia (Figure 3 ).

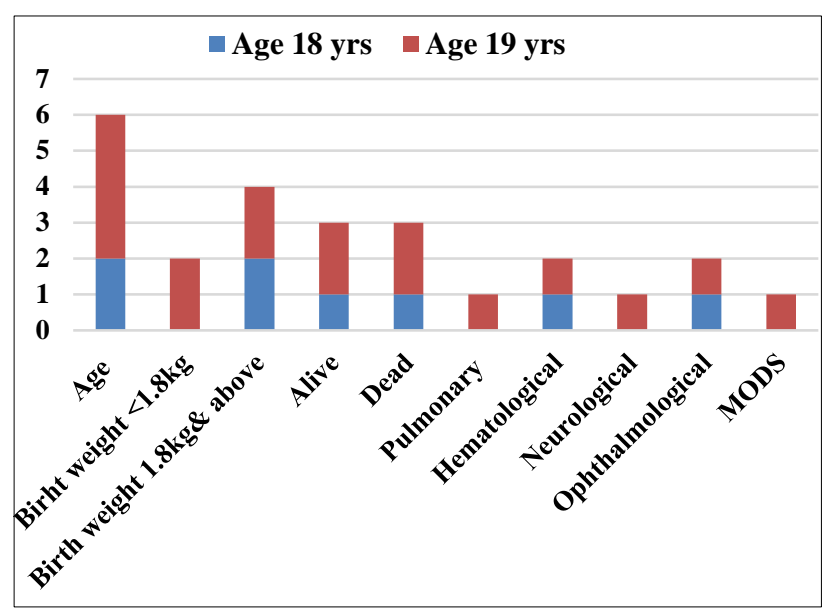

Teenage women with complications, associated with preeclampsia/ eclampsia formed $5.5 \%(\mathrm{n}=6)$ of the study group. All 6 babies were male. 2 babies were born with birth weight less than $1.8 \mathrm{kgs}$. 4 babies were born with birth weight $1.8 \mathrm{kgs}$ and above. 3 babies were born alive. 3 babies were dead born.

Figure 2: Maternal and neonatal outcome in teenage mothers with preeclampsia/eclampsia.

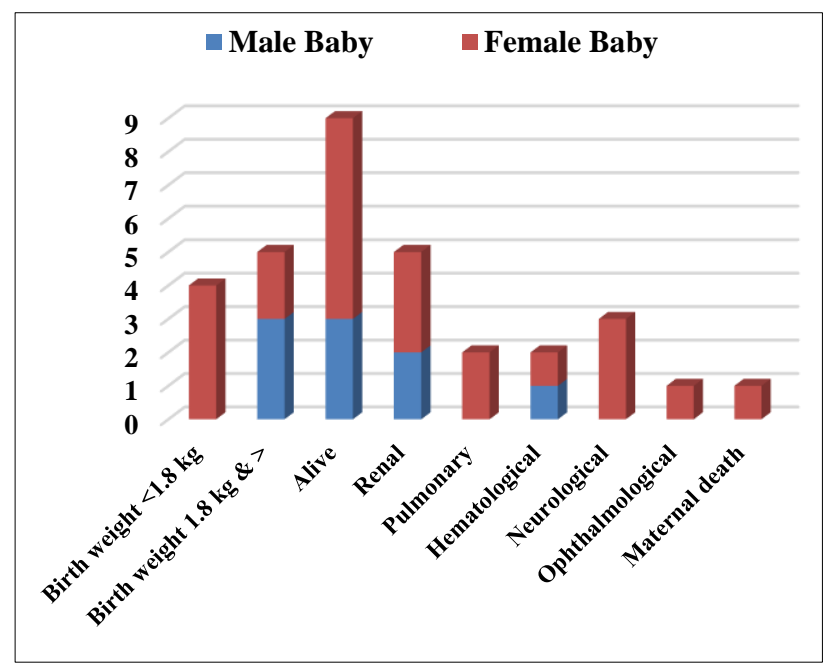

Elderly women with complications, associated with preeclampsia and eclampsia formed $8.3 \%$ of the total group. 4 babies were born with birth weight less than $1.8 \mathrm{kgs}$. 5 babies were born with birth weight more than $1.8 \mathrm{kgs}$ and above. All 9 babies were born alive

Figure 3: Pregnancy outcome in elderly women. 
We sought to find out if there was any correlation between complications developing in preeclampsia and eclampsia women and sex of the baby. When we analysed the records of women who developed complications following preeclampsia and eclampsia, it was observed that $62.3 \%$ of women delivered female babies. Of the group of female babies, $41.1 \%$ of babies were born with birth weight less than $1.8 \mathrm{~kg} .58 .8 \%$ of babies were born with birth weight 1.8 $\mathrm{kg}$ and above. $78 \%$ of babies were born alive. $22 \%$ of babies were dead born. Renal complications were seen in $38.2 \%$ of women. Pulmonary complications were seen in $16.2 \%$ of women. Hematological complications were seen in $32.4 \%$ of women. Neurological complications were seen in $25 \%$ of women. Ophthalmological complications were seen in $8.8 \%$ of women. Septic complications were seen in $8.8 \%$ of women and multi organ dysfunction syndrome were seen in $5.8 \%$ of women (Figure 4). There were 4 maternal deaths.

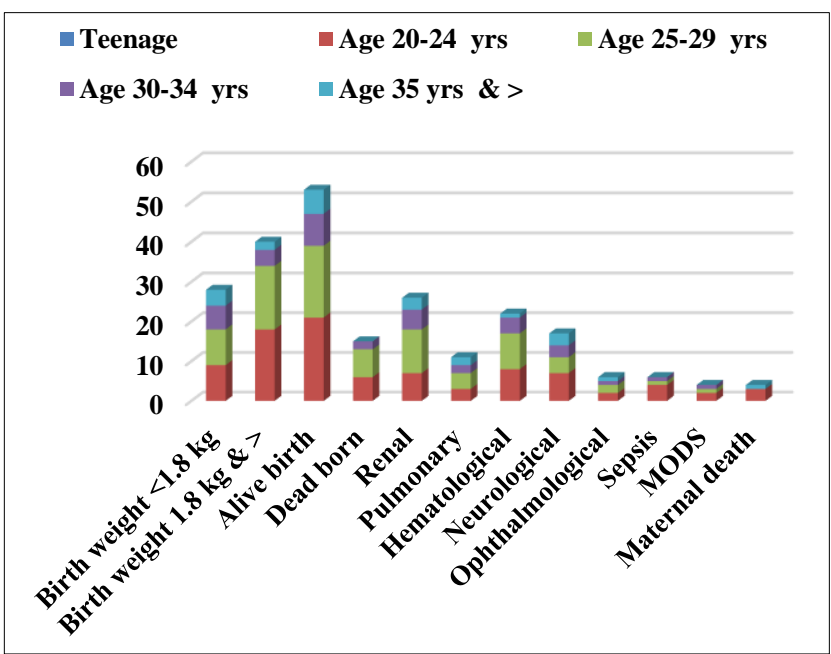

More complications were observed among the group of mothers who delivered female babies. Of the total no. of 68 female babies born, 28 babies were born with birth weight less than 1.8 kgs. 40 babies were born with birth weight $1.8 \mathrm{~kg}$ and above. 53 babies were born alive. 15 babies were dead born

Figure 4: Perinatal outcome and complications in mothers of female babies.

There were some differences noted in the outcome in mothers who delivered male babies, as compared to mothers who gave birth to female babies. $37.6 \%$ of the total number of babies born were male. In this group of male babies, $31.7 \%$ of babies were born with birth weight less than $1.8 \mathrm{~kg}$. $68.2 \%$ babies were born with birth weight $1.8 \mathrm{~kg}$ and above. $65.8 \%$ babies were born alive. $34.1 \%$ babies were dead born. Neurological complications were seen in $29.2 \%$ of women. Pulmonary complications were seen in $17.1 \%$ women. Hematological complications were seen in $36.5 \%$ women. Ophthalmological complications were seen in $14.6 \%$ women. Multi organ dysfunction syndrome is seen in $4.8 \%$ women. Renal complications were seen in $29.2 \%$ women (Figure 5). ${ }^{8}$ There were two maternal deaths.

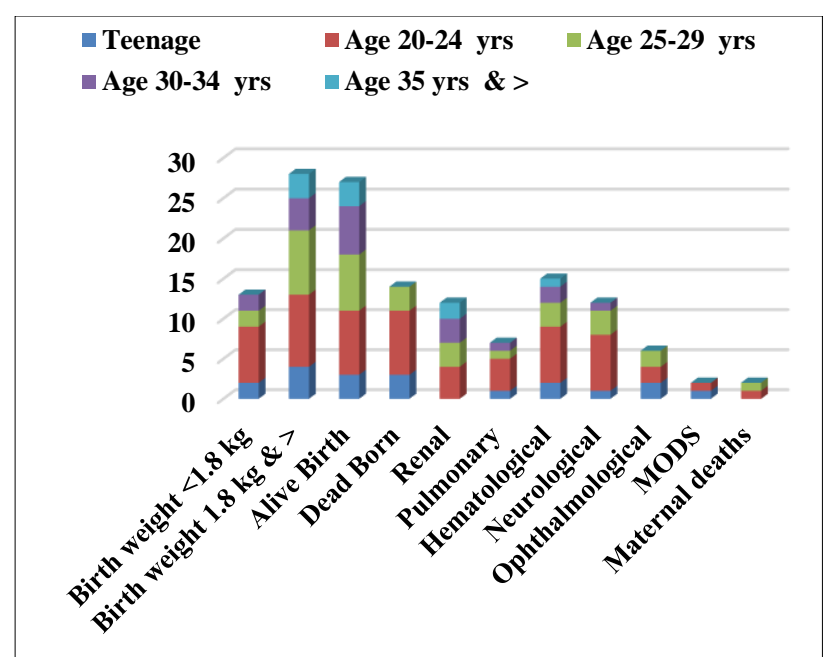

Perinatal outcome of male babies: Of 41 male babies, 13 babies had a birth weight less than $1.8 \mathrm{kgs}$. and 28 babies were born with birth weight $1.8 \mathrm{kgs}$ and above. 27 babies were born alive. 14 babies were dead born. Complications observed among the group of mothers who delivered male babies were, Renal complications in 12 women, pulmonary complications in 7 women, hematological complications in 15 women, neurological complications in 12 women, ophthalmological complications in 6 women, and multi organ dysfunction syndrome in 2 women

\section{Figure 5: Perinatal outcome and complications in mothers of male babies.}

\section{Maternal mortality}

There was a total of 18 maternal deaths recorded for the year 2018, in our centre. Of these, a large number of almost $34 \%$ [ $n=6$ ] of maternal deaths were caused by complications associated with severe preeclampsia and eclampsia. Nearly $67 \%(n=4)$ of these women, were referred very late to our institution and the mothers could not be saved. In all women there were at least more than two complications which led to death. A superimposed complication of sepsis was seen in 2 women. The cause of death in these women was pulmonary complications along with neurological complications and HELLP syndrome in three women. Neurological and Renal complications, and precipitating Multi organ dysfunction syndrome was the cause of death in three women.

\section{Perinatal details}

Two babies, one male and one female, were born alive. It is important to note here that both live babies had birth weight of $3.4 \mathrm{~kg}$ and $3.3 \mathrm{~kg}$ respectively. Four babies were dead born, of which three were female and one was a male baby. In this study group, the maternal mortality was $5.5 \%$, among women who developed complications associated with preeclampsia or eclampsia. ${ }^{9}$

How do we address the very common complication of preeclampsia and eclampsia in women? 
It is seen that preeclampsia and eclampsia remain a significant cause of maternal morbidity and mortality till today. ${ }^{10}$ It would be best to start preventive measures even before conception, to all women planning pregnancy and especially in women with predisposing risk factors of future development of preeclampsia and eclampsia. ${ }^{11}$ Women with raised blood pressure, prior to pregnancy should receive adequate care and attention with great detail for preventing development of complications associated with preeclampsia. ${ }^{12}$ Eclampsia can develop at any time before, during or after parturition. The warning signs should be identified early and every effort should be taken to prevent eclampsia. Urinary infections, a common complaint of young women and especially among women who conceive soon after marriage, with untreated urinary infections are at a risk to develop Preeclampsia. ${ }^{13}$ Smaller medical centres should be alert in identifying preeclampsia early and refer women at risk to a well-equipped tertiary care hospital which could be the preferred treatment and management center for this complication in birthing women. ${ }^{14}$

\section{CONCLUSION}

In this one-year study, 2511 women were admitted with the complication of preeclampsia or eclampsia. A large number of 109 women developed complications because of preeclampsia and/ or eclampsia.

In the year 2018, in our centre a significant number of maternal deaths forming nearly $34 \%$ was caused by complications which had developed because of preeclampsia or eclampsia. Nearly, $62.3 \%$ of babies born had a birth weight of $1.8 \mathrm{~kg}$ and above, and $26.6 \%$ babies were dead born.

Major maternal complications noted were renal complications in $34.8 \%$, hematological complications in $33 \%$, neurological complications in $25.6 \%$, pulmonary complications in $16.5 \%$, ophthalmological complications in $11 \%$, Sepsis in $6.4 \%$ and MODS in $10 \%$ of women with preeclampsia or eclampsia. Complications of preeclampsia were more often present in mothers of female babies $(62.4 \%)$ in contrast to those of mothers of male babies (37.6\%). Among female babies, $78 \%$ were born alive and $58.8 \%$ had birth weight more than $1.8 \mathrm{~kg}$. The perinatal outcome among male babies observed was, $65.8 \%$ live births and $68.2 \%$ had birth weight more than $1.8 \mathrm{~kg}$. There were no maternal deaths among teenage mothers.

The complications associated with preeclampsia and eclampsia of pregnancy are a major cause of morbidity and mortality in both mother and baby. Common complaints, such as urinary infections, raised blood pressure should be detected and treated. Every effort should be made to identify preeclampsia and warning signs of eclampsia early and refer women at risk to wellequipped tertiary care hospitals which could be the preferred treatment and management centers for this complication in birthing women.

\section{ACKNOWLEDGMENTS}

Authors would like to thank the Director, IOG for granting permission to conduct this study. The authors also thank Dr. DM Christe, NIRRH-FU, ICMR for her guidance in conducting this study.

\section{Funding: No funding sources}

Conflict of interest: None declared

Ethical approval: The study was approved by the Institutional Ethics Committee

\section{REFERENCES}

1. Paauw ND, Lely AT. Cardiovascular sequels during and after preeclampsia. In: Kerkhof P., Miller V. (eds) sex-specific analysis of cardiovascular function. Adv Exper Med Biol Springer Cham. 2018;1065.

2. Lu Y, Chen R, Cai J, Huang Z, Yuan H. The management of hypertension in women planning for pregnancy. Br Med Bull. 2018;128(1):75-84.

3. Portelli M, Baron B. Clinical presentation of preeclampsia and the diagnostic value of proteins and their methylation products as biomarkers in pregnant women with preeclampsia and their newborns. J Preg. 2018:Article ID 2632637.

4. Garg RK, Kumar N, Malhotra HS. Posterior reversible encephalopathy syndrome in eclampsia. Neurol India. 2018;66(5):1316-23.

5. Tang $\mathrm{P}$, Wang J, Song Y. Characteristics and pregnancy outcomes of patients with severe pneumonia complicating pregnancy: a retrospective study of 12 cases and a literature review. BMC Preg Childbirth. 2018;18:434.

6. Komine-Aizawa S, Aizawa S, Hayakawa S. Periodontal diseases and adverse pregnancy outcomes. J Obstet Gynaecol Res. 2019;45(1):5-12.

7. Parikh P, Blauwet L. Peripartum cardiomyopathy and preeclampsia: overlapping diseases of pregnancy. Curr Hypertens Rep. 2018;20:69.

8. Calimag-Loyola APP, Lerma EV. Renal complications during pregnancy: In the hypertension spectrum. Dis Mon. 2019;65(2):25-44.

9. Konopka WD, Laskowska M, Oleszcuk J. Preeclampsia-current management and future approach. Curr Pharm Biotechnol. 2018;19(10):78696.

10. Malika A, Jeeb B, Gupta SK. Preeclampsia: disease biology and burden, its management strategies with reference to India. Preg Hypertens. 2019;15:23-31.

11. Uzan J, Carbonnel M, Piconne O, Asmar R, Ayoubi JM. Pre-eclampsia: pathophysiology, diagnosis, and management. Vasc Health Risk Manag. 2011;7:46774. 
12. Bortolotto MR, Francisco RPV, Zugaib M. Resistant hypertension in pregnancy: how to manage? Curr Hypertens Rep. 2018;20:63.

13. Yan L, Jin Y, Hang H, Yan B. The association between urinary tract infection during pregnancy and preeclampsia: a meta-analysis. Med. 2018;97(36):e12192.
14. Khidri Ff. Various presentations of preeclampsia at tertiary care hospital of Sindh: a cross-sectional study. Current Hypertens Rev. 2019;15:1.

Cite this article as: Thiripurasundari G, Christe DM, Shobha S, Sangeetha V, Sevugaperumal S.

Complications and pregnancy outcome in women with preeclampsia and eclampsia. Int J Reprod Contracept Obstet Gynecol 2020;9:294-9. 